\title{
Preparing a Rat Brain Tissue Samples for Acetylcholinesterase Activity Measurement - the MM method
}

\author{
Sonja Marinković, ${ }^{1}$ Đorđe Đukanović, ${ }^{1}$ Nebojša Mandić-Kovačević, ${ }^{2}$ Tanja \\ Cvjetković, ${ }^{3}$ Snežana Uletilović, ${ }^{3}$ Žana M Maksimović ${ }^{1}$
}

\section{Abstract}

Background/Aim: Organophosphorus compounds (OP) bind to acetylcholinesterase (AChE) causing an irreversible inhibition of the enzyme. When doing in vivo studies of OP intoxication, to precisely measure AChE activity in the brain tissue it is necessary to remove as much blood from the brain as possible. By doing so, interference of the OPs present in the blood is avoided. Usually this demands expensive equipment, therefore, the aim of this study was to find a simple and economical method to eliminate the blood from brain blood vessels.

Methods: Wistar albino rats were divided into four groups named Control (C), Control washout (CW), Paraoxon (Pox) and Paraoxon washout (PoxW) group. Rats in Pox and PoxW were treated with $0.25 \mathrm{mg} / \mathrm{kg}$ paraoxon subcutaneously (sc), while $\mathrm{C}$ and $\mathrm{CW}$ received $1 \mathrm{~mL} / \mathrm{kg}$ sc saline instead. The "Marinković-Maksimović" ("MM") method was performed in rats from PoxW and CW groups. Activity of AChE was measured both in erythrocyte lysate and in brain tissue using spectrophotometry.

Results: Macroscopic examination revealed that the elimination of blood was achieved in CW and PoxW groups. Activity of AChE in homogenised brain tissue was expectedly lower in the Pox and PoxW group, when compared to $\mathrm{C}$ and $\mathrm{CW}$ group, respectively. The CW group had a lower value of AChE activity in the brain tissue compared to C group, while activity of AChE in the PoxW group was statistically higher than in the Pox group $(\mathrm{p}=0.044)$.

Conclusion: The MM method provides good elimination of blood from the brain. Together with blood, present confounding factors that interfere with analysis in homogenised brain tissue, were also eliminated.

Key words: Organophosphorus compounds; Oximes; Acetylcholinesterase; Enzyme activity; Rat brain.

\section{Introduction}

Organophosphorus compounds (OP) are synthetic compounds first synthesised in the 1930s, that are vastly used as pesticides, but also developed as warfare nerve agents. ${ }^{1}$ OP poisoning causes about $3,000,000$ acute intoxications annually, 300,000 of which lead to fatalities. ${ }^{2}$ They bind to the serine group of acetylcholinesterase (AChE),
(1) Centre for Biomedical Research, Faculty of Medicine, University of Banja Luka, Banja Luka, the Republic of Srpska, Bosnia and Herzegovina.

(2) Department of Pharmacy, Faculty of Medicine, University of Banja Luka, Banja Luka, the Republic of Srpska, Bosnia and Herzegovina.

(3) Faculty of Medicine, University of Banja Luka, Banja Luka, the Republic of Srpska, Bosnia and Herzegovina.

Correspondence:

SONJA MARINKOVIĆ

E: sonja.trbojevic@med.unibl.org

ARTICLE INFO

Received: 21 December 2021 Revision received: 22 December 2021 Accepted: 25 December 2021 
postsynaptic receptors causing acute cholinergic effects. ${ }^{4}$ OPs are mostly lipophilic substances that penetrate the blood-brain barrier (BBB) easily. ${ }^{5}$ More lipophilic OPs are vastly distributed in fat tissue, from which they are gradually released to re-inhibit AChE. This leads to a prolonged inhibition of AChE and slower elimination of OPs. ${ }^{6}$

OP-AChE bonds can be reactivated by oximes. As such, they are an important therapeutic agent in the therapy of OP intoxication. ${ }^{5}$ Unlike the OPs, oximes generally have a low degree of penetration through the BBB, because of which they have little to no ability to reactivate brain AChE. ${ }^{7}$ Knowing that central respiratory depression is a main cause of death in OP intoxication, ${ }^{8,9}$ when researching a new oxime, it is very important to determine the degree of its penetration through the BBB. Finding an oxime that is more penetrable, would mean a greater therapeutic success.

In animal models of OP intoxication, to determine the level of AChE inhibition in the central nervous system, a brain tissue is homogenised and the homogenate is analysed for AChE activity. To get accurate test results, it is necessary to remove as much blood from the brain tissue sample as possible. Otherwise, test results would be altered because of the OPs present in blood. ${ }^{10}$ When searching the literature on this matter, a method of circulatory perfusion using an isotonic buffer solution and a Masterflex pump (Cole-Parmer, Chicago, IL, USA) was found. ${ }^{11}$ As such equipment was not available to us at short notice, the aim of this study was to find a simple and affordable method for circulatory perfusion of Wistar albino rat brain.

\section{Methods}

\section{Experimental animals}

Wistar albino rats, male and female, weighing between 260 - $350 \mathrm{~g}$ were used. The animals were housed 4 per cage, in air-conditioned rooms with controlled temperature $\left(21 \pm 1^{\circ} \mathrm{C}\right)$ and a $12 \mathrm{~h}$ light/dark cycle. They had access to food and water ad libitum. For this study ethical approval was given by the Ethics Committee for the Protection and Welfare of Experimental Animals in Biomedical Research, Faculty of Medicine, University of Banja Luka (Decision No 18/1/20). During the entire experiment, the "Guiding principles in the care of and use of laboratory animals" have been observed.

\section{Experimental protocol}

To determine the efficacy of the circulatory perfusion method, rats were divided into 4 groups, 2 animals each. Groups were named Control (C), Paraoxon (Pox), Control with washout (CW) and Paraoxon with washout (PoxW). Rats in the Pox and PoxW group were treated with $0.25 \mathrm{mg} / \mathrm{kg}$ ( $0.25 \mathrm{mg} / \mathrm{mL}$ solution) paraoxon (Sigma Aldrich, St Louis, MO, USA) subcutaneously (sc), while C and CW groups received $1 \mathrm{~mL} / \mathrm{kg}$ sc of saline instead. Half an hour later, rats were anaesthetised using $90 \mathrm{mg} / \mathrm{kg}$ ketamine and $10 \mathrm{mg} / \mathrm{kg}$ xylazine administered intraperitoneally (ip). The rat thoracic cavity was opened and blood samples were collected from the vena cava inferior into Lithium Heparin plasma tubes after which the animals were sacrificed via exsanguination. The "MM" method was performed in the rats from both PoxW and CW groups. Brains from both groups were excised, including cerebrum, cerebellum and the truncus encephali and stored at $-20{ }^{\circ} \mathrm{C}$ until homogenisation.

\section{The Marinković-Maksimović method (MM method)}

To access the rat heart and major blood vessels the rats were tied to operating boards $15 \times 25 \mathrm{~cm}$ in size. A skin and muscle incision was made just below the processus xiphoideus using large surgical scissors. Next, bilateral incisions were made, following the medial axillary line. After separating the diaphragm from the anterior thoracic wall, the semi-attached anterior thoracic wall was clamped and put away to leave a clear operating field (Figure 1). To achieve exsanguination, inferior vena cava was cut just above the liver.

Prior to the cannulation of the aorta, a $10 \mathrm{~cm}$ long thread was pulled under the ascending aorta. Using microscissors a small diameter incision (approx. 1-2 $\mathrm{mm}$ ) was made in the anterior wall of the ascending aorta, just above the aortic root. The tip of the cannulation tube was then inserted into the lumen of the aorta, making sure that it does not surpass the point of the first aortic arch branch (Figure 2). Using the earlier prepared tread, the tube was tied into place. The abdominal aorta was clamped, to ensure that the saline used for washout goes only to the upper half of the body. Also, to achieve a free outflow of saline 


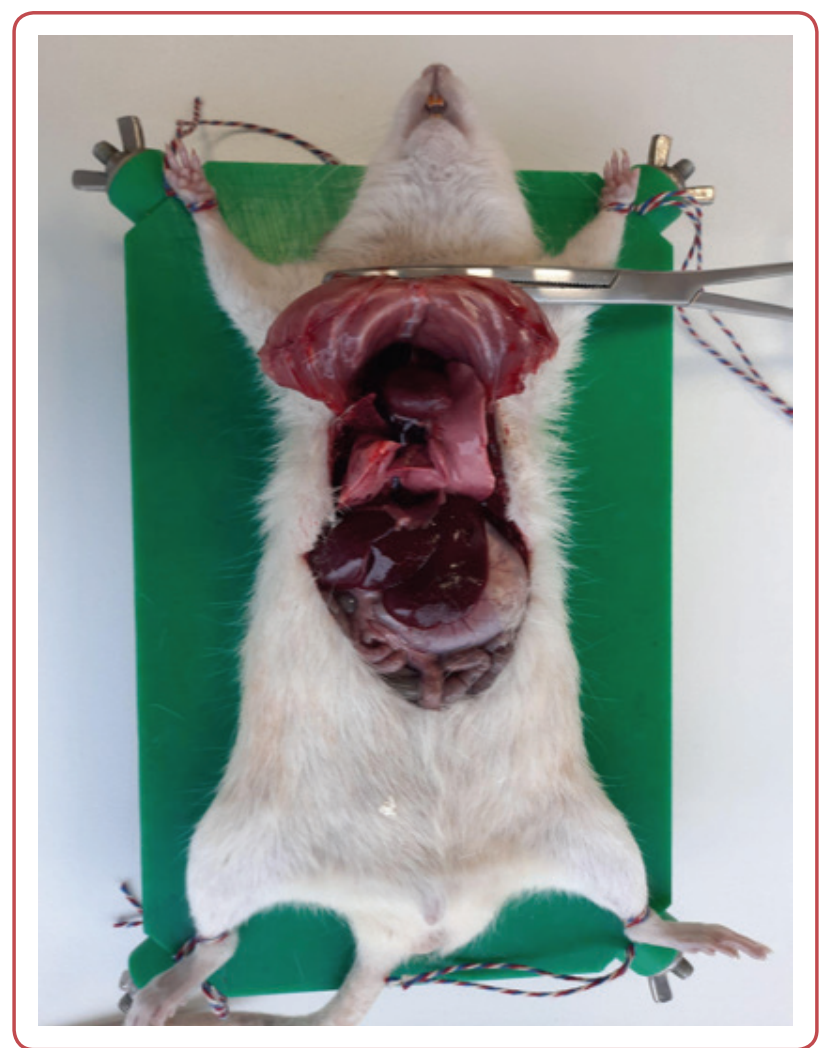

Figure 1: Access to the thoracic cavity of the rat

solution, superior vena cava was cut just above the heart. The upper body blood vessels were then perfused with a total of $100 \mathrm{~mL}$ of saline through the cannulation system, using $10 \mathrm{~mL}$ syringes (Figure 3). The efficiency of perfusion is observed during the procedure itself by observing the eyeballs of rats - pallor indicates the elimination of blood from the blood vessels of the eye (Figure 4).

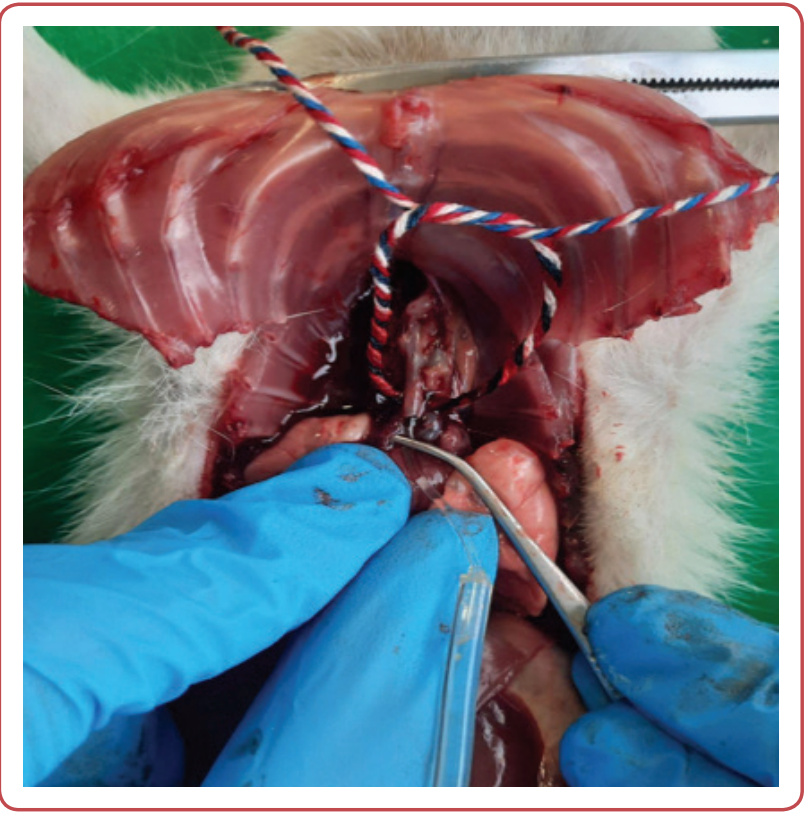

Figure 2: Cannulation of the rat aorta

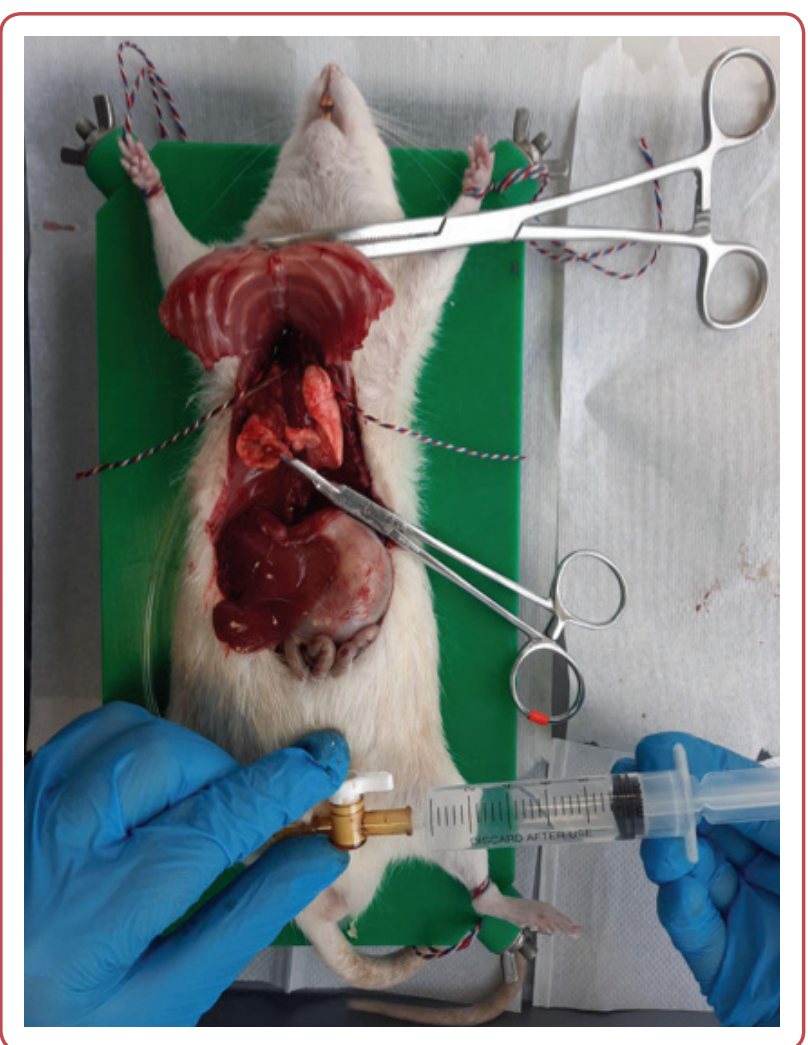

Figure 3: Washout procedure

Tissue homogenisation and measuring of the AChE activity

The right side cerebrum, cerebellum and truncus encephali, priorly frozen at $-20^{\circ} \mathrm{C}$ were cut into smaller tissue fragments and weighted. Fragments were then mixed with phosphate buffer $(0.1 \mathrm{M}, \mathrm{pH} 8.0)$ in a $1: 20$ ratio and homogenised at 10,000 rpm for 1 minute. Cold chain was main-

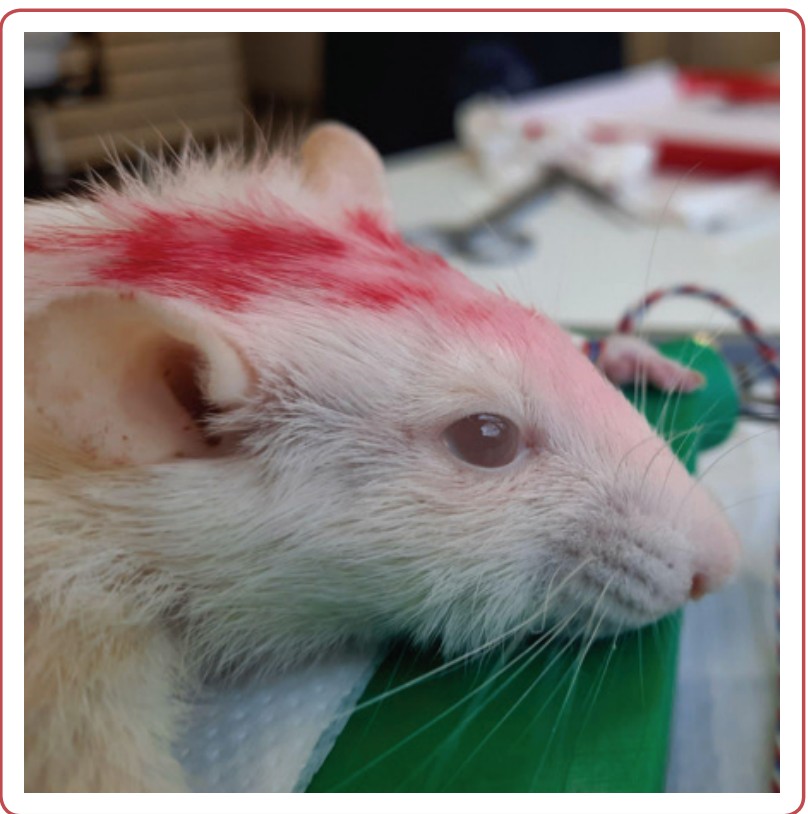

Figure 4: Iris pallor observed after implementation of the "MM" method 
tained during the whole procedure. Homogenised tissue was centrifuged at $4{ }^{\circ} \mathrm{C}$, for 15 minutes at $15,000 \mathrm{rpm}$ and the supernatant was used as a sample for determining AChE activity in the brain tissue.

The AChE activity was measured by the Ellman colorimetric method using a Shimadzu UV-1800 spectrophotometer (Kyoto, Japan) and UV Probe 2.17 software (Kyoto, Japan). ${ }^{12}$ Activity was determined from the brain tissue samples and from blood samples (erythrocyte lysate). Activity of AChE in erythrocyte lysate was expressed as $\mu \mathrm{mol} / \mathrm{min} / \mathrm{mL}$, while its activity in the brain tissue was expressed as $\mu \mathrm{mol} / \mathrm{min} / \mathrm{g}$.

\section{Statistical analysis}

Normality of data was analysed and confirmed by Kolmogorov-Smirnov test. Appropriate parametric test was performed (Student t-test). Data were shown as mean values with their standard deviations (SD). Statistical significance was set at $p<0.05$. IBM SPSS version 23.0 for Windows software was used for data analysis.

\section{Results}

Macroscopic examination of the brain indicated that good elimination of blood from brain tissue was achieved by washout (Figure 5).

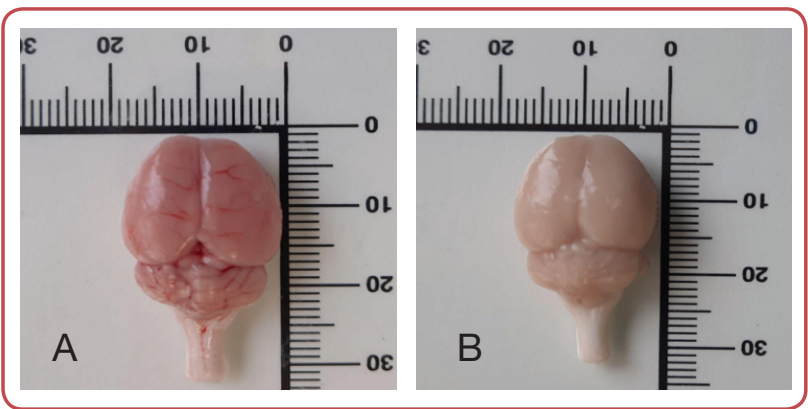

Figure 5: Macroscopic results of the "MM" method. The macroscopic difference in appearance of the rat brain from the control group (A) and from the control with washout group (B)

Detailed values of weight, brain weight and AChE activity for each experimental animal are given in Table 1.

No significant difference in mean values of rat brain mass between groups with and without washout was found $(t=2.29, p=0.262)$. There was no significant difference between mean values of AChE activity in erythrocytes between C and CW group (Student t-test: $\mathrm{t}=0.88, \mathrm{p}=0.472$ ), as well as between Pox and PoxW group $(\mathrm{t}=0.45$, $p=0.708$ ) (Figure 6).

Table 1: Acetylcholinesterase (AChE) values in rat brain and erythrocytes related to treatment

\begin{tabular}{|c|c|c|c|c|c|}
\hline Group & Rat No & $\begin{array}{l}\text { Rat } \\
\text { mass (g) }\end{array}$ & $\begin{array}{l}\text { Rat brain } \\
\text { mass (g) }\end{array}$ & $\begin{array}{l}\text { AChE } \\
\text { activity in } \\
\text { erythrocyte } \\
\text { ( } \mu \mathrm{mol} / \\
\mathrm{min} / \mathrm{mL} \text { ) }\end{array}$ & $\begin{array}{l}\text { AChE } \\
\text { activity in } \\
\text { brain tissue } \\
\text { ( } \mu \text { mol/ } \\
\text { min/g) }\end{array}$ \\
\hline \multirow{2}{*}{ C } & 1 & 263 & 1.92 & 3.36 & 1.63 \\
\hline & 2 & 271 & 1.84 & 2.99 & 1.26 \\
\hline \multirow{2}{*}{ CW } & 3 & 342 & 2.16 & 2.76 & 1.50 \\
\hline & 4 & 354 & 2.30 & 3.13 & 1.11 \\
\hline \multirow{2}{*}{ Pox } & 5 & 271 & 2.30 & 2.24 & 0.92 \\
\hline & 6 & 350 & 2.13 & 2.61 & 0.89 \\
\hline \multirow{2}{*}{ PoxW } & 7 & 307 & 2.02 & 2.24 & 1.05 \\
\hline & 8 & 315 & 2.02 & 2.99 & 1.01 \\
\hline
\end{tabular}

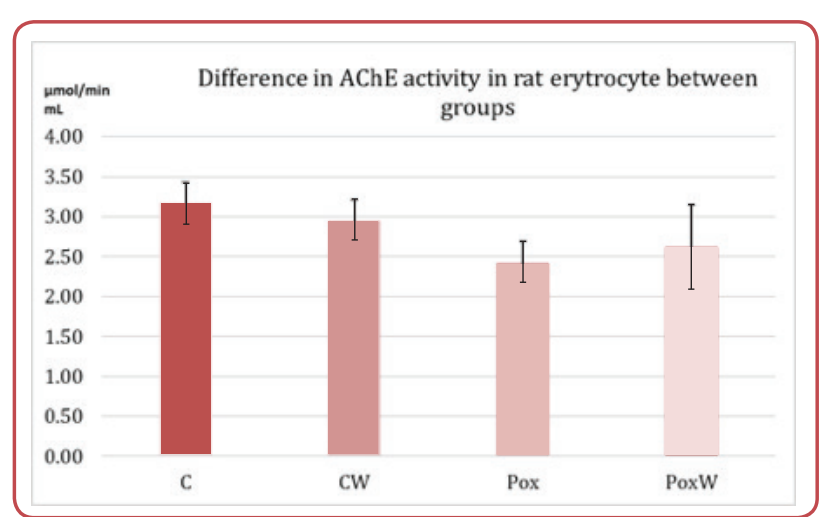

Figure 6: Acetylcholinesterase (AChE) activity in the rat erythrocyte lysate samples

C - control group; CW - control with washout group; Pox - paraoxon group; PoxW - paraoxon with washout group.

Values are presented as mean values \pm standard deviations;

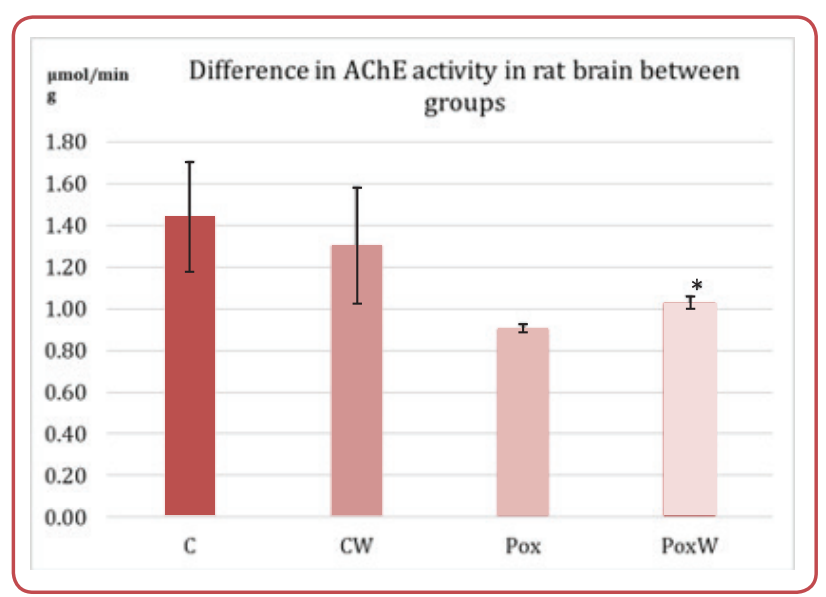

Figure 7: Acetylcholinesterase (AChE) activity in the rat brain tissue samples

C - control group; CW - control with washout group; Pox - paraoxon group; PoxW - paraoxon with washout group;

Values are presented as mean values \pm standard deviations;

${ }^{*}$ There was significant difference between AChE activity in rat brain between Pox and PoxW group (Student $t$-test: $t=5.00, p=0.044$ ). 
There was no significant difference between mean values of AChE activity in rat brain between C and CW group (Student t-test: $t=0.52$, $p=0.655)$, but there was significant difference between Pox and PoxW group $(t=5.00, p=0.044)$ (Figure 7).

\section{Discussion}

When analysing the AChE activity in brains of rats poisoned with OP and treated with oximes, the presence of blood in the brain can distort the results for several reasons, primarily due to lipophilicity of OPs and poor penetration of oximes through the BBB. Following absorption, OPs accumulate rapidly in fat, liver, kidneys and salivary glands. Lipophilic OPs are released more slowly from adipose tissue and have a milder acute but prolonged effect. When the applied oxime reactivates AChE, the leakage of lipophilic OPs from the depot re-inhibits AChE. Paraoxon (diethyl (4-nitrophenyl) phosphate) is the active metabolite of the OP insecticide parathion. ${ }^{13}$ The phosphorothioates $(\mathrm{P}=\mathrm{S})$ (eg, diazinon, parathion) are more lipophilic than phosphates $(\mathrm{P}=0)(\mathrm{eg}$, dichlorvos, paraoxon). Spontaneous reactivation of dimethyl-phosphorylated AChE often occurs rapidly even without oxime therapy. There is no such expectation for AChE inhibited with diethyl phosphoryl insecticides. ${ }^{5}$

How to increase therapeutic potential of oxime, by improving their BBB penetration remains a challenge in modern toxicology. As a very selectively permeable membrane, the BBB imposes several limitations for oxime penetration to the brain tissue, such as hydrophilicity, polarity and molecule size. Consequently, pyridinium aldoximes (PyAls) such as pralidoxime (2-PAM) have a very low rate of BBB penetration, ${ }^{14,15}$ which is mostly associated with their high hydrophilicity $^{10}$ and permanent cationic charge. 2-PAM, which is most commonly used oxime in the treatment of OP poisonings, has a relatively low level of transport through the BBB. ${ }^{15-17}$

Respiratory failure has been identified in numerous studies as the leading cause of death in OP poisoning. ${ }^{18-20}$ Houze et $\mathrm{al}^{21}$ have shown that respiratory failure is most likely the result of central respiratory depression, rather than peripheral bronchoconstriction, bronchorrhoea and respiratory muscle fatigue. ${ }^{8,9}$ Knowing that, a crucial point in therapy would be reactivation of AChE in brain tissue. ${ }^{15}$ Because of that, non-quaternary organic compounds are introduced as novel antidotes in OP poisoning. ${ }^{22,}{ }^{23}$ Not having a quaternary group gives them a better penetrability through the BBB. Data from the literature indicate that the chlorine atoms in the oxime increase its lipophilicity. ${ }^{24}$ In OP insecticides, it has been shown that oximes with a functional group at the position 4 reactivate $\mathrm{OP}$ insecticides most effectively. Oximes with a bis-quaternary structure are more efficient than those ones with mono-quaternary structure. It is best that linker has 3-5 C-C connections. The double bond in the linker increases both their efficiency and toxicity. ${ }^{25,26}$

There are several ways to determine the efficiency of brain AChE reactivation by oximes, but most widely used is an indirect method. With this method the level of BBB of an oxime penetration is measured by the level of $\mathrm{AChE}$ reactivation in the brain tissue. To achieve precise results, it is necessary to remove blood from the brain. This way OPs present in the blood will not interfere with the results. Washing out blood from the brain by using the "MM" procedure, showed reduced detected AChE activity in homogenised brain tissue, which resulted in $0.15 \mu \mathrm{mol} / \mathrm{min} / \mathrm{g}$ difference between control groups (C and CW). This decrease was due to the removing of the AChE present in red blood cells, whose activity could be measured in the brain homogenate in the absence of washing out. In both groups treated with paraoxon AChE activity was expectedly lower when compared with controls $337.24 \%$ drop when comparing $C$ and Pox group and 21.37 $\%$ difference between CW and PoxW). Comparing the results between Pox and PoxW group, AChE activity has remained higher in the PoxW group that was subjected to the "MM" procedure. Evidently the washout prevented remaining paraoxon from blood to bind with AChE and thus to distort the level of AChE activity in the brain after homogenisation.

By introducing the "MM" method, few things were tried to be avoided; one of them is that OP re-arrives from the blood into the brain to re-inhibit the AChE, thus obtaining lower values of AChE activity than the real ones. On the other hand, a new oxime that would penetrate BBB better could reactivate AChE in the brain. The presence of blood in homogenates would call into question 
the origin of reactivated AChE - by eliminating the blood, the obtained values of AChE activity are those from the brain and not from the blood and brain.

\section{Conclusion}

The "MM" method provides good elimination of blood from the rat brain and thus eliminates confounding factors in the analysis of parameters from brain homogenates. The introduction of the procedure in the Centre for Biomedical Research, Faculty of Medicine, University of Banja Luka enables the universality of the procedure and the reproducibility of the results.

\section{Acknowledgements}

We would like to thank the Centre for Biomedical Research, Medical Faculty, University of Banja Luka, for providing us with the space, equipment and experimental animals. We would also like to thank Professor Rajko Igic, for sending to us the plastic tubing without whom the method would not have been possible.

\section{Conflict of interest}

The authors declare that there are no conflicts of interest. This study is partially funded by the Ministry of Scientific and Technological Development, Higher Education and Informational Society of the Government of the Republic of Srpska (Grant No 125 7030).

\section{References}

1. Stojiljković MP. Nerve agents - a clear and present danger to mankind. Scr Med 2019;50(3):109-11.

2. Eddleston M, Phillips MR. Self poisoning with pesticides. BMJ 2004 Jan 3;328(7430):42-4.

3. Worek F, Diepold C, Eyer P. Dimethylphosphoryl-inhibited human cholinesterases: inhibition, reactivation, and aging kinetics. Arch Toxicol 1999 Feb;73(1):7-14.

4. Maksimović ŽM, Jović-Stošić J, Vučinić S, Perković-Vukčević N, Vuković-Ercegović G, Škrbić R, et al.
Acute organophosphate and carbamate pesticide poisonings - a five-year survey from the National Poison Control Centre of Serbia. Drug Chem Toxicol 2021 Dec 7:1-9. doi: 10.1080/01480545.2021.2012481.

5. Vale JA. Toxicokinetic and toxicodynamic aspects of organophosphorus (OP) insecticide poisoning. Toxicol Lett 1998 Dec 28;102-103:649-52.

6. Tsatsakis AM, Manousakis A, Anastasaki M, Tzatzarakis M, Katsanoulas K, Delaki C, et al. Clinical and toxicological data in fenthion and omethoate acute poisoning. J Environ Sci Health B 1998 Nov;33(6):657-70.

7. Norrrahim MNF, Razakb MAIU, Shahc NAA, Kasimc H, Yusoffc WYW, Halim NA. Recent developments on oximes to improve the blood brain barrier penetration for the treatment of organophosphorus poisoning: a review. RSC Adv 2020;10:4465-89.

8. Rickett DL, Glenn JF, Beers ET. Central respiratory effects versus neuromuscular actions of nerve agents. Neurotoxicology 1986 Spring;7(1):225-36.

9. Škrbić R, Stojiljković MP, Ćetković SS, Dobrić S, Jeremić D, Vulović M. Naloxone antagonizes soman-induced central respiratory depression in rats. Basic Clin Pharmacol Toxicol 2017 Jun;120(6):615-20.

10. Kalász H, Nurulain SM, Veress G, Antus S, Darvas F, Adeghate E, et al. Mini review on blood-brain barrier penetration of pyridinium aldoximes. J Appl Toxicol 2015 Feb;35(2):116-23.

11. Orct T, Jurasović J, Micek V, Karaica D, Sabolić I. Macro- and microelements in the rat liver, kidneys, and brain tissues; sex differences and effect of blood removal by perfusion in vivo. J Trace Elem Med Biol 2017 Mar;40:104-11.

12. Ellman GL, Courtney KD, Andres V Jr, Feather-Stone RM. A new and rapid colorimetric determination of acetylcholinesterase activity. Biochem Pharmacol 1961 Jul;7:88-95.

13. Maksimović ŽM, Duka D, Bednarčuk N, Škrbić R, Stojiljković MP. Onset rate and intensity of signs of organophosphate poisoning related to paraoxon dose and survival in rats. Scr Med 2021 Mar;52(1):49-58.

14. Wei Z, Liu YQ, Wang YA, Li WH, Zhou XB, Zhao J, et al. Novel nonquaternary reactivators showing reactivation efficiency for soman-inhibited human acetylcholinesterase. Toxicol Lett 2016 Mar 30;246:1-6.

15. Sakurada K, Matsubara K, Shimizu K, Shiono H, Seto Y, Tsuge K, et al. Pralidoxime iodide (2-PAM) penetrates across the blood-brain barrier. Neurochem Res 2003 Sep;28(9):1401-7.

16. Firemark H, Barlow CF, Roth LJ. The penetration of 2-PAM-c14 into brain and the effect of cholinesterase inhibitors on its transport. J Pharmacol Exp Ther 1964 Aug;145:252-65.

17. Petroianu G, Toomes LM, Petroianu A, Bergler W, Rufer R. Control of blood pressure, heart rate and haematocrit during high dose intravenous paraoxon exposure in mini pigs. J Appl Toxicol 1998;18:293-8.

18. Eddleston M, Eyer P, Worek F, Mohamed F, Senarathna L, von Meyer L, et al. Differences between organophosphorus insecticides in human self-poisoning: a prospective cohort study. Lancet 2005 Oct 22-28;366(9495):1452-9.

19. Namba T, Nolte CT, Jackrel J, Grob D. Poisoning due to organophosphate insecticides. Acute and chronic manifestations. Am J Med 1971;50(4):475-92.

20. Ballantyne B, Marrs TC. Overview of the biological and clinical aspects of organophosphates and carbamates. In: Ballantyne B, Marrs TC, eds. Clinical and experimental toxicology of organophosphates and carbamates. Oxford: Butterworth-Heinemann; 1992. p. 3-14. 
21. Houze P, Pronzola L, Kayouka M, Villa A, Debray M, Baud FJ. Ventilatory effects of low-dose paraoxon result from central muscarinic effects. Toxicol Appl Pharmacol 2008 Dec 1;233(2):186-92.

22. Dube SN, Ghosh AK, Jeevarathinam K, Kumar D, Das Gupta S, Pant BP, et al. Studies on the efficacy of diethyxime as an antidote against organophosphorus intoxication in rats. Jpn J Pharmacol 1986;41:267-71.

23. de Koning MC, van Grol M, Noort D. Peripheral site ligand conjugation to a non-quaternary oxime enhances reactivation of nerve agent-inhibited human acetylcholinesterase. Toxicol Lett 2011 Sep 25;206(1):54-9.

24. Zorbaz T, Malinak D, Maraković N, Maček Hrvat N, Zandona A, Novotny M, et al. Pyridinium oximes with ortho-positioned chlorine moiety exhibit improved phys- icochemical properties and efficient reactivation of human acetylcholinesterase inhibited by several nerve agents. J Med Chem 2018 Dec 13;61(23):10753-66.

25. Musilek K, Dolezal M, Gunn-Moore F, Kuca K. Design, evaluation and structure-activity relationship studies of the AChE reactivators against organophosphorus pesticides. Med Res Rev 2011 Jul;31(4):548-75.

26. Kuca K, Jun D, Junova L, Musilek K, Hrabinova M, da Silva JAV, et al. Synthesis, biological evaluation, and docking studies of novel bisquaternary aldoxime reactivators on acetylcholinesterase and butyrylcholinesterase inhibited by paraoxon. Molecules 2018 May 7;23(5):1103. doi: 10.3390/molecules23051103. 